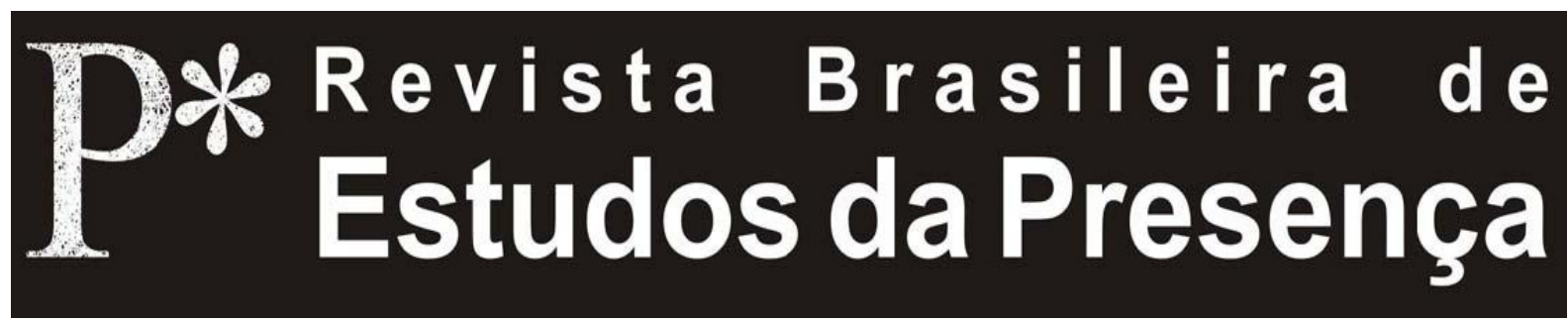

DOI - http://dx.doi.org/10.1590/2237-266027225

ISSN 2237-2660

\title{
Breve Notícia de uma Adolescente Transdisciplinar: a etnocenologia
}

Armindo Jorge de Carvalho Bião Universidade Federal da Bahia - UFBA, Salvador, BA, Brasil

RESUMO - Breve Notícia de uma Adolescente Transdisciplinar: a etnocenologia - Este texto apresenta um panorama da Etnocenologia sob diferentes prismas. Evidenciam-se as atividades fundadoras dessa disciplina e discutem-se as bases históricas sob as quais ela está acentada. Problematiza-se e desenha-se a posição da disciplina segundo os aspectos epistemológicos e transdisciplinares, salientando-se as vocações, conflitos e características da produção etnocenológica, em especial, no Brasil e na França.

Palavras-chave: Etnocenologia. Pesquisa. Performance. Espetáculo.

ABSTRACT - Brief Report on a Transdisciplinary Teenager: ethnoscenology - This text presents an overview of Ethnoscenology from different angles. It identifies the founding activities of this field and discusses its historical basis, questioning and drawing up the position of the individual according to epistemological and transdisciplinary aspects, highlighting the vocations, conflicts and characteristics of ethnoscenological production, especially in Brazil and France.

Keywords: Ethnoscenology. Research. Performance. Spectacle.

RÉSUMÉ - Brève Notice sur une Adolescente Transdisciplinaire: l'ethnoscénologie - Ce texte présente un panorama de l'ethnoscénologie sous différents angles, mettant en évidence les activités fondatrices de cette discipline et proposant une réflexion sur les bases historiques sur lesquelles elle s'appuie. Il soulève la problématique et cherche à cerner le positionnement de la discipline à partir de notions épistémologiques et transdisciplinaires, soulignant les vocations, les conflits et les caractéristiques de la production ethnoscénologique, en particulier au Brésil et en France.

Mots-clés: Ethnoscénologie. Recherche. Performance. Spectacle. 
A etnocenologia merece uma reflexão de caráter críticohistórico, ainda que breve, no contexto de um número temático da Revista Brasileira de Estudos da Presença, da Universidade Federal do Rio Grande do Sul, sobre Etnocenologia e Educação, antes de completar a maioridade de 18 anos, comemorando seu nascimento em 1995. Seu berço é o contexto diplomático da UNESCO, numa articulação institucional entre a educação (a multicultural e histórica Paris VIII, criada em 1968 em Vincennes, hoje Université de Paris Nord Villetaneuse Saint Denis) e a cultura (a Maison des Cultures du Monde, fundada em 1982 para dialogar com as artes do espetáculo de todo o mundo $)^{1}$. Por isso, inicialmente, vale enfatizar sua vocação de berço, para a diplomacia, a vida acadêmica e o intercâmbio cultural. E questionar: como tem se realizado esta vocação?

Outras aparentes vocações, certamente, merecem também reflexão e questionamento. Tanto as de caráter epistemológico, sobre sua posição de encruzilhada entre as artes e as ciências e entre a teoria e a prática, aparentemente incontestadas, quanto as de caráter pragmático e, possivelmente por isso mesmo, mais polêmico. Essas se resumem na possível integração do âmbito profissional das artes do espetáculo com seus paralelos dos âmbitos artístico-experimental, universitário e, sobretudo, o dos folguedos, ancorados na tradição cultural local e em suas experiências e expressões de música, dança e representação.

E, finalmente, uma discussão, já iniciada em seu colóquio fundador, sobre os possíveis conflitos e alianças entre as novas tecnologias de comunicação e as artes do espetáculo, que, do mesmo modo, merece muita atenção e deve ser motivo da conclusão desta breve reflexão sobre a adolescente transdisciplinar, que é a etnocenologia.

A vocação para a vida acadêmica parece estar bem confirmada, com a consolidação, ao menos, de dois polos na França e dois no Brasil, respectivamente as universidades de Paris Nord Villetaneuse Saint Denis e de Nice Sophia Antipolis e as Federais da Bahia (UFBA) e do Pará (UFPA). Esses polos internacionais se interconectam em rede (que se estende pela Bélgica, Itália, Inglaterra, Uruguai, Chile, Coreia, China...), através da orientação de teses e dissertações, 
da realização de eventos, residências e missões de trabalho e da integração de grupos de pesquisa, não somente entre si, mas também com diversas outras instituições universitárias, não só da França e do Brasil. Aqui, desde 2007, a Associação Brasileira de Pesquisa e Pós-Graduação em Artes Cênicas, a ABRACE, abriga um Grupo de Trabalho, cujos líderes se encontram nas Universidades Federais do Rio Grande Sul (UFRGS), de Brasília (UNB), de Minas Gerais (UFMG) e do Estado do Rio de Janeiro (UNIRIO). Assim, a articulação da etnocenologia com a educação formal, particularmente a de nível de pós-graduação (e, secundariamente, de graduação), fica evidenciada como vocação e futuro históricos.

Quanto à vocação para a diplomacia, nestes 17 anos, a realização de seis colóquios internacionais confirma os polos originais da etnocenologia, a UFBA (em 1997 e 2007) e Paris VIII (em 1995 e 2008), que são a sede, cada uma, de dois desses colóquios internacionais. O II, que aconteceu em Cuernavaca, Morelos, México (em 1996), numa instituição de caráter mais cultural que educacional, sugere a ratificação dessa vocação. E o III Colóquio, em Belo Horizonte, Minas Gerais (em 2009), indica, por um lado, o peso do Brasil para a plena efetivação dessa vocação e, por outro lado, a força da vocação da etnocenologia para a vida acadêmica. No entanto, a interrupção da sequência de colóquios entre 1998 e 2006, que passaram de anuais para bienais, demonstra o desafio que é a manutenção de sua vocação para a diplomacia, inclusive porque a participação de pesquisadores vinculados ao mundo árabe, nesses eventos, praticamente cessou durante o período no qual não foram realizados colóquios internacionais.

Já a vocação para o intercâmbio cultural, no que tange ao âmbito mais estritamente artístico, parece ser uma grande frustração. De fato, provavelmente o elevado custo de transporte e recepção de artistas atuantes numa determinada cidade (ou região, ou país), dificultando o deslocamento de seus espetáculos, restringe esse intercâmbio aos artistas universitários, que, individualmente, podem apresentar parte de suas práticas artísticas nos eventos acadêmicos.

As vocações de caráter epistemológico, por sua vez, se beneficiam da tendência internacional para as proposições 
multi, inter e transdisciplinares, mas também sofrem de sua posição de encruzilhada. Ademais, a diversidade de estrutura institucional universitária, entre a França e o Brasil, por exemplo, contribui para esse sofrimento. E, acrescente-se, as semelhanças e diferenças entre a etnocenologia, os estudos da performance e a antropologia da performance, associadas à voga internacional do uso dos múltiplos conceitos de performance e aos problemas habituais de tradução linguística e cultural, aportam muito à confusão epistemológica. Assim, no Brasil, onde a etnocenologia se encontra, como em toda parte, no âmbito das artes, e onde é mais comum (que na França, por exemplo) a integração entre teoria e prática no ambiente universitário, acontece naturalmente, tanto pragmaticamente quanto em termos epistemológicos e metodológicos.

Já a articulação entre as artes e as ciências, no Brasil, se dá sem problemas no discurso e encontros dos pesquisadores de etnocenologia com seus pares dos estudos e da antropologia da performance e, de modo incipiente, com os pesquisadores da neurociências. O mesmo ocorre na França, onde, no entanto, ocorre, efetivamente, em termos de diálogo, uma maior integração dos pesquisadores da etnocenologia com seus colegas das neurociências. Para uma proposição transdisciplinar ainda jovem e, possivelmente, ainda num estado pré-paradigmático, trata-se, sem dúvida, de uma grande performance (num sentido de desempenho, realização).

As vocações de caráter pragmático da etnocenologia são polêmicas, mesmo em nível epistemológico, desde seu evento de instalação, com posições antagônicas daqueles que propõem restringi-la ao âmbito não acadêmico e artístico-experimental e daqueles que a consideram também objeto de estudo (possivelmente por se tratarem de pesquisadores artistas profissionais). Já o trato do que, circunstancialmente, pareceria ser o objeto por excelência da pesquisa, os folguedos ancorados na tradição cultural local e em suas experiências e expressões de música, dança e representação, tem se consolidado como perspectiva ontológica, ainda que com nuances.

No Brasil, por exemplo, a investigação de fenômenos espetaculares do próprio país é moeda corrente e valorizada, 
assim como não é incomum a pesquisa sobre fenômenos espetaculares de caráter acadêmico e/ou artístico-profissional, inclusive envolvendo o próprio pesquisador artista. Enquanto que na França persiste o interesse por fenômenos exóticos e etnografias densas feitas, de maneira absolutamente majoritária, por teóricos. Assim, essa vocação de caráter pragmático, de possível integração do âmbito profissional das artes do espetáculo com seus paralelos dos âmbitos artístico-experimental, universitário e, sobretudo, do universo lúdico de recriação dinâmica das tradições vivenciadas e expressas em formas musicais, coreográficas e representacionais, parece permitir diferentes combinações, confirmando-se em sua diversidade de construção de um verdadeiro mosaico ontológico, baseado nas diferentes culturas e estruturas institucionais onde ocorre a pesquisa em etnocenologia.

Finalmente, a discussão iniciada em seu colóquio fundador, sobre os possíveis conflitos e alianças entre as novas tecnologias de comunicação e as artes do espetáculo, parece ter perdido fôlego. Talvez até porque seu uso corrente nas redes de pesquisa em etnocenologia tem familiarizado os pesquisadores com seus benefícios e complicações. No entanto, se, do ponto de vista ontológico, os fenômenos espetaculares que reúnem num mesmo espaço e tempo presencial todos os interessados (artistas, técnicos e púbico responsáveis por sua existência) permanecem sua referência central, as novas tecnologias, enquanto ferramenta de pesquisa, para o registro desses fenômenos e, também, como meio para sua difusão e estímulo ao prestígio no imaginário social, parecem se impor como opção válida.

A adolescente transdisciplinar já está a merecer um inventário das teses, dissertações, artigos em periódicos e livros que dela tratam, até porque já se constitui em verbete nos dicionários especializados mais importantes em língua portuguesa (Guinsburg, 2006, p. 139) e em língua francesa (Pavis, 1996, p. 125; desde sua primeira edição; Corvin, 2008, p. 524-525; e em suas edições mais recentes - as anteriores, de 1991 a 2006, ignoravam a etnocenologia). A realização do VII Congresso da ABRACE, na UFRGS, em Porto Alegre-RS, 
de 7 a 11 de outubro de 2012 e, do VII Colloque international d'ethnoscénologie, na Maison des Sciences de l'Homme Paris Nord, de 22 a 24 de maio de 2013, deverá contribuir para, enfim, o acesso à maioridade dessa jovem transdisciplinar, ultrapassando a crise da adolescência e, assumindo-se, ainda, pré-paradigmática. 


\section{Nota}

${ }^{1}$ No espaço virtual <www.etnocenologia.org>, desde 2009, encontra-se vasta bibliografia de caráter histórico e de resultados de pesquisa em etnocenologia, inclusive os anais dos colóquios internacionais realizados em 2007, em Salvador-BA e 2009, em Belo Horizonte-MG. Do mesmo modo, estão accessíveis, em <www.portalabrace.org>, os trabalhos apresentados no Grupo de Trabalho de Etnocenologia da ABRACE, em seus eventos anuais de 2008 a 2011. 


\section{Referências}

CORVIN, Michel (Org.). Dictionnaire Encyclopédie du Théâtre à Travers le Monde. Paris: Bordas; SSEJER, 2008.

GUINSBURG, Jacob et al. (Org.). Dicionário de Teatro Brasileiro: temas, formas e conceitos. São Paulo: Perspectiva, 2006.

PAVIS, Patrice. Dictionnaire du Théâtre. Paris: Dunod, 1996.

Armindo Jorge de Carvalho Bião é ator, encenador e professor titular associado da Universidade Federal da Bahia e pesquisador $1^{\text {a }}$ do CNPq. Foi professor visitante na Université de Paris 8 Nord Villetaneuse Saint Denis; na Université Ouverte des CinqContinents em Mali; na Universidad de Alcalá de Henares e Ateneo de Madrid; no Instituto Politécnico de Leiria em Portugal; na Université de Nice Sophia Antipolis, na Universität Goethe Frankfurt am Main na Alemanha e na Université Libre de Bruxelles, na Bélgica. É formado em filosofia pela Universidade Federal da Bahia, mestre em Artes pela University of Minnesota e doutor em Antropologia Social e Sociologia Comparada pela Université René Descartes Paris V Sorbonne com pós-doutorado em Estudos Teatrais pela Université de Paris Ouest Nanterre La Défense, na França.

E-mail: biao.armindo@gmail.com

Recebido em janeiro de 2012 Aprovado em abril de 2012 